\title{
First Year Courses in IT: A Bloom Rating
}

\section{Dave Oliver and Tony Dobele School of Computing Sciences, Central Queensland University, Rockhampton, QLD, Australia}

\section{d.oliver@cqu.edu.au t.dobele@cqu.edu.au}

\begin{abstract}
This paper explores the cognitive difficulty of assessment tasks in six first year computing courses within an Information Technology (IT) degree. Bloom's taxonomy is used as an analytical framework. A Bloom rating is calculated for each of the courses involved in the study and the results are presented and analysed. A wide variation in the cognitive level and style of assessment is revealed. These results are also compared to those from an earlier study and a reduction in the cognitive level of first year programming courses in this study is detected.
\end{abstract}

Keywords: Blooms Taxonomy, First year, IT, education, evaluation

Full version of this paper has been fast-tracked for publication in the Journal of IT Education 